\title{
Comparison of Using an Electronic System and Conventional Monitoring Method for Monitoring the Quality of Drinking Water and Defects Discovery in Rural Area Water Distribution Network of Abarkouh, Iran
}

\author{
Reza Ali Fallahzadeh', Maryam Gholami'2, Elham Madreseh ${ }^{3}$, Mohammad Taghi Ghaneian', \\ Mohamad Hadi Farahzadi4*, Ali Akbar Askarnejad5, Shahram Sadeghi' \\ ${ }^{1}$ Department of Environmental Health Engineering, School of Public Health, Shahid Sadoughi University of \\ Medical Sciences, Yazd, Iran \\ ${ }^{2}$ Department of Environmental Health Engineering, Abarkouh Paramedical School, Shahid Sadoughi University \\ of Medical Sciences, Yazd, Iran \\ ${ }^{3}$ Department of Epidemiology and Biostatistics, School of Health, Tehran University of Medical Sciences, \\ Tehran, Iran \\ ${ }^{4}$ Department of Neuroscience, School of Advanced Technologies in Medicine, Tehran University of Medical \\ Sciences, Tehran, Iran \\ ${ }^{5}$ Abarkouh Health Network, Shahid Sadoughi University of Medical Sciences, Yazd, Iran \\ ${ }^{6}$ Department of Environmental Health Engineering, School of Public Health, Student Research Committee, \\ Kurdistan University of Medical Sciences, Sanandaj, Iran \\ Email: fallahzadeh4@yahoo.com
}

Received 14 October 2014; revised 30 November 2014; accepted 17 December 2014

Copyright (C) 2015 by authors and Scientific Research Publishing Inc.

This work is licensed under the Creative Commons Attribution International License (CC BY).

http://creativecommons.org/licenses/by/4.0/

c) (i) Open Access

\section{Abstract}

The used water for human consumption must be free of microorganisms and chemicals that cause risk in the human health. In this study, water quality of 18 rural area of Abarkouh was determined and compared the conventional monitoring method (According to ISIR (Institute of Standards and Industrial Research of Iran), 1053 and 4208) and use of electronic system method (Patent in industrial property general office of Iran, 77815). Free chlorine monitoring and $\mathrm{pH}$ test done by health workers in the conventional method and the results will be sent to the Health Network monthly. Sampling for microbiological testing is done monthly based on population (According to ISIR, 4208). On the electronic system, the procedure is also done by health workers, but the result

"Corresponding author.

How to cite this paper: Fallahzadeh, R.A., et al. (2015) Comparison of Using an Electronic System and Conventional Monitoring Method for Monitoring the Quality of Drinking Water and Defects Discovery in Rural Area Water Distribution Network of Abarkouh, Iran. Health, 7, 35-40. http://dx.doi.org/10.4236/health.2015.71005 
will be sent to the receiver device by using a cell phone. According to the chlorine test results if the free chlorine residual reported zero, microbiological sampling was done by a health expert. Finally, the number of chlorine test and microbiological sampling and the results of these experiments collected in the both methods and recorded in SPSS 22 then were analyzed by using chi-square test and Fisher exact test. The result of microbiological experiments shows that the sampling rate decreased $29 \%$ in using of electronic system method in comparison to the conventional monitoring method while the number of microbial defect detection increased $19 \%$ in drinking water networks monitoring by electronic system. Using of electronic system monitoring can reduce the rate and cost of microbiological sampling and its experiments and increase accuracy of these tests, in this way it will increase the quality and safety of drinking water in distribution network in small and dispersed rural communities.

\section{Keywords}

Water Distribution Network, Monitoring, Microbiological Experiments, Water Quality, Rural Area

\section{Introduction}

According to definition of the World Health Organization (WHO), drinking water is the water that is suitable for human consumption and all domestic applications; it is available in sufficient quantity and appropriate quality [1]. The used water for human consumption must be free of microorganisms and chemicals that cause risk in human health. Absences of turbidity, color, smell and unpleasant taste are the most important parameters in quality of public drinking water sources [2]. According to a joint report by the Asian Development Bank (ADB) [3], the Office of the United Nations Development Planning (UNDP) [4], the United Nations Economic and Social Commission for Asia and the Pacific (UNESCAP) [3], and the World Health Organization (WHO) [5], nearly 83 percent of the Iranian rural population had access to safe drinking water. According to the report, the index is also predicted 83 percent in 2015 [3]. The accessibility indicator of safe drinking water in rural areas in Iran was 67.48 percent in 2006 [4]. The most important cause of outbreaks waterborne disease is pollution in distribution water networks. So, one of the main topics of quality control unit is paying attention to the quality of drinking water in distribution water network [6].

In rural areas, distribution and water quality monitoring is essential due to various problems such as Nonhomogeneous distribution in both the geographic dispersion of rural villages and residential space in a rural location, deterioration of facilities and distribution water networks and lack of proper care ..., proximity livestock and humans, waste dispersion into the environment and low-level public health [7]. In Iran, sampling for microbial test and chlorine test done in health centers without detailed schedule based on population distribution and inflexible geographic zoning. Lack of involvement of other parameters to determine the right time and place of sampling, paper recording of chlorine and $\mathrm{pH}$ test result and lack of involvement of this analyzed results in sampling for microbiological test and causes the sampling with low value in statistical analysis and high costs. Use of an electronic system with the capability of recording and analyzing the results of chlorine test not only enhances the accuracy of microbial experiments but also reduces experiment costs [9]. So far, many methods and devices are provided for water quality monitoring in consumer units [9], monitoring and recording the chlorine in water networks [10], and water networks monitoring in the presence of leaks [11].

The aim of this study was to compare the efficiency of the electronic system monitoring [12] for chlorine and $\mathrm{pH}$ in drinking water by conventional method of drinking water quality monitoring which is a non-electronic method.

\section{Material and Methods}

In this study, two methods for water quality monitoring were utilized simultaneously in quality monitoring of 18 rural areas of Abarkouh (Figure 1). In this case, free chlorine in distribution water network was measured daily as routinely work of health workers by the usual colorimetric method by using of tablets called DPD No. 1 (diethyl-p-phenylenediamine indicator tablet) and a standard kit manufactured by Palintest of Britain according to 
ISIR No. 1053. At the end of month, the result of this test was sent to health office in the classification forms. Microbiological sampling and experiments of determined rural drinking water networks were performed by 5 tubes microbial test in the presumptive test stage according to rural population (According to ISIR, No. 4208, Sampling of water for microbiological test). Simultaneously, the electronic system (that made by this project executor and patent in industrial property general office of Iran by No. 77815) (Figure 2 and Figure 3) was utilized. In the electronic systems operation used cell phone to send data. Health workers trained on how to send data in a training session before applying the electronic system. Health workers were obliged to send the sampling location code, $\mathrm{pH}$ and free residual chlorine were measured by SMS (Short Message Service) to receiver board daily.

Data received by the central system and information such as sampling location name, date and time of sampling, the range of $\mathrm{pH}$ and residual chlorine content was visible on the software. User checked this information on the computer monitor regularly and if the free residual chlorine was zero, in coordination with the health center expert, taken microbial samples of site and send to laboratory.

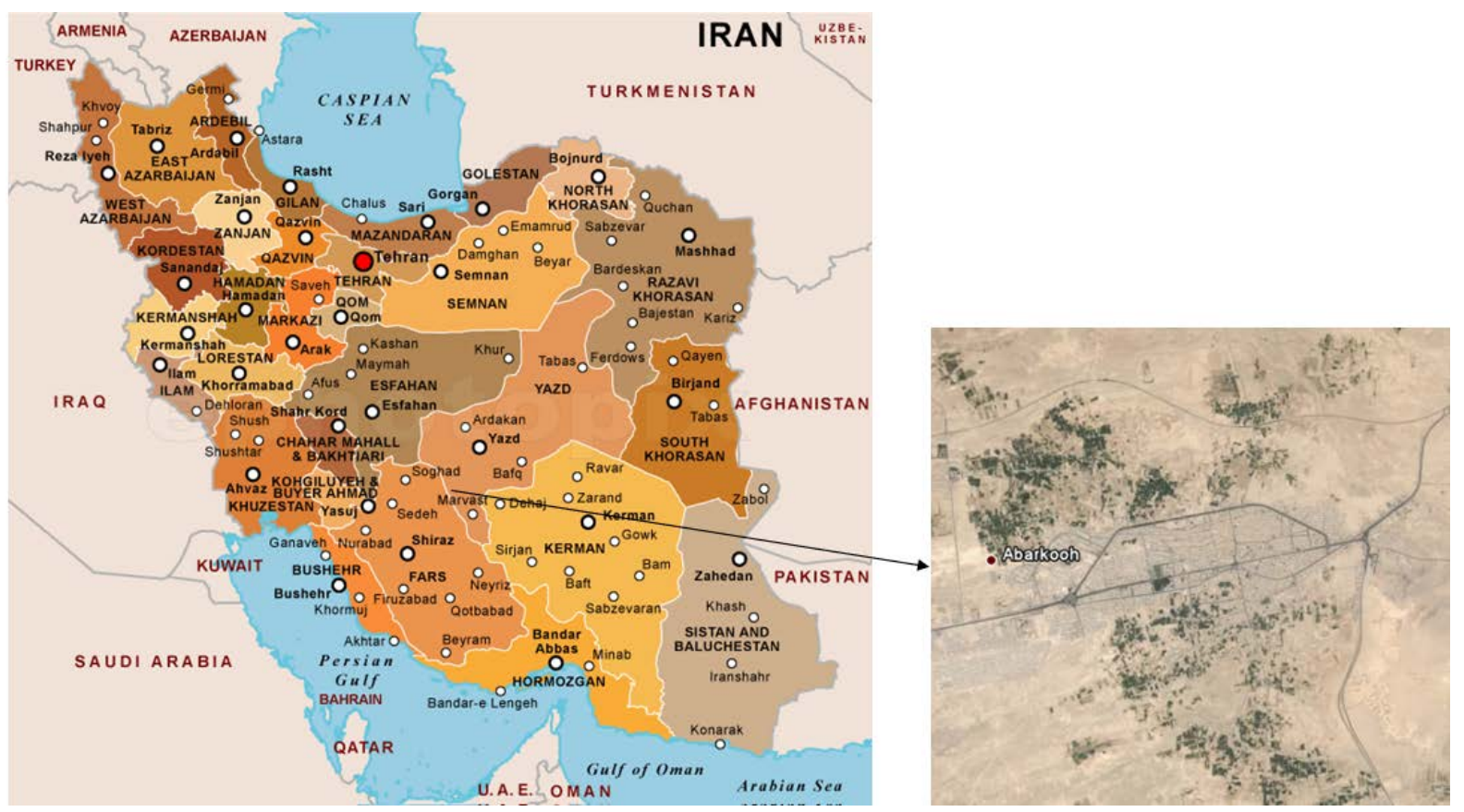

Figure 1. Location of Abarkouh in the map of Iran.
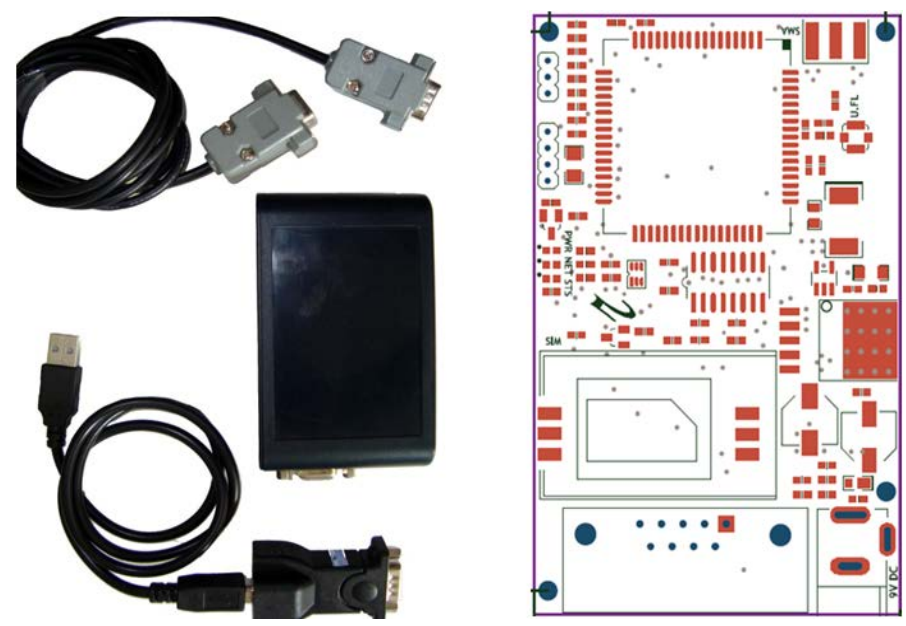

Figure 2. Receiver board in electronic system. 
The experiments were carried out over June, 2014. Finally the data of chlorine and microbial testing obtained by both methods were collected and submitted in SPSS 22 software, then were analyzed by chi-square test and Fisher exact test. The significance level was considered 0.05 .

\section{Findings}

Of 615 total chlorine tests recorded by conventional monitoring methods, the free residual chlorine was unfavorable (least than $0.2 \mathrm{mg} / \mathrm{L}$ ) in 52 cases (8.5\%); However in 652 tests that recorded by the electronic system, 61 cases of defects were reported (9.4\%). According to this result, electronic system has more accuracy (1\%) in defects detection. However, it has not statistically significant difference with conventional monitoring method. a comparison to the abundance of microbial tests in both methods showed, of 24 and 17 samples that have been tested by the conventional method and electronic systems respectively, in the first method 1 test (2.4\%) and in electronic systems method 4 test (23.5\%) showed the presence of Coliform organisms in water (Table 1). Although according to reporting defect in microbial testing, the electronic system method had more accurate (19\%) than the conventional method, but the rate was not statistically significant (P-value $>0.05)$.

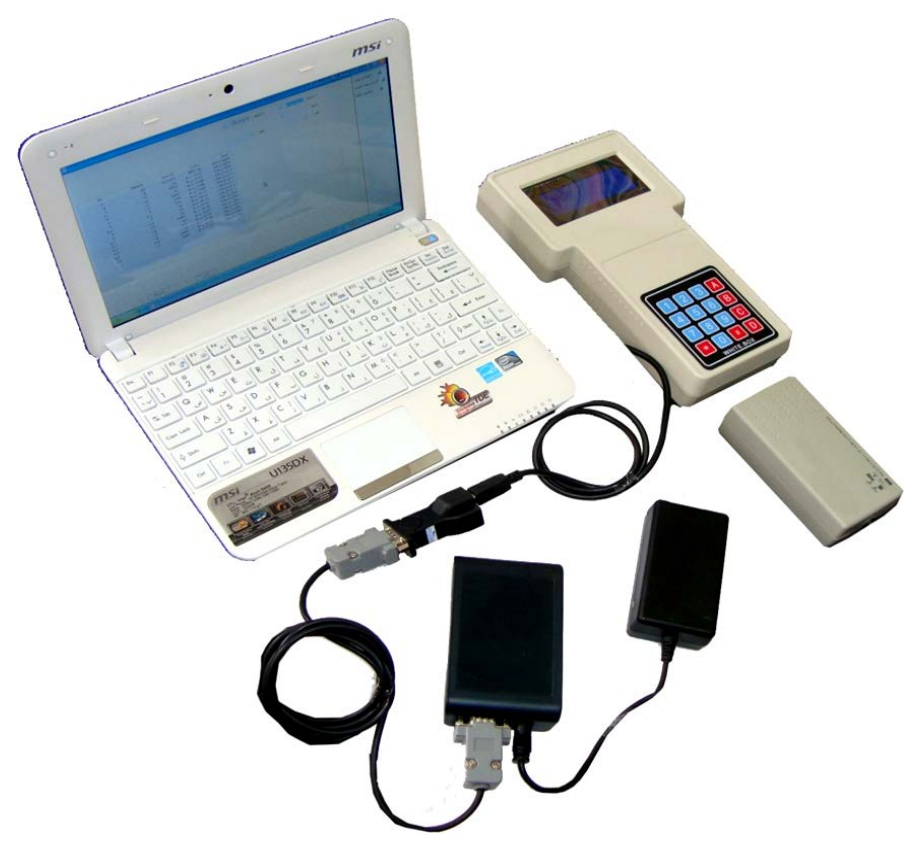

Figure 3. All part of electronic system.

Table 1. The comparison of health defect detection frequency in conventional monitoring method and electronic system monitoring method in chlorine and microbial tests separately.

\begin{tabular}{|c|c|c|c|c|}
\hline & \multirow[b]{2}{*}{ Type of test } & \multicolumn{2}{|c|}{ Type of monitoring } & \multirow[b]{2}{*}{ P-value } \\
\hline & & $\begin{array}{l}\text { Conventional } \\
\text { method (n\%) }\end{array}$ & $\begin{array}{l}\text { Electronic system } \\
\text { method (n\%) }\end{array}$ & \\
\hline \multirow{3}{*}{ Chlorine test } & Favorable chlorine $(0.2-0.8 \mathrm{mg} / \mathrm{L})$ & $563(91.5)$ & $591(90.6)$ & \multirow{3}{*}{$0.574^{*}$} \\
\hline & Unfavorable chlorine (Out of range 0.2 - 0.8) & $52(8.5)$ & $61(9.4)$ & \\
\hline & Total & $615(100)$ & $652(100)$ & \\
\hline \multirow{3}{*}{ Microbial test } & Presence of Coliform (Total Coliform) & $1(4.2)$ & $4(23.5)$ & \multirow{3}{*}{$0.141^{* *}$} \\
\hline & Absence of Coliform & $23(95.8)$ & $13(76.5)$ & \\
\hline & Total & $24(100)$ & $17(100)$ & \\
\hline
\end{tabular}

"Chi-square test; ${ }^{* *}$ Fisher's exact test. 


\section{Discussion}

Based on the findings, it concludes that the electronic system can reduce the number of sampling to 7 cases (29\% reducing). Naturally, it will also reduce the costs of sampling and microbial tests. While the number of microbial defects discovery increased (19.3\%) in rural drinking water network monitoring. this increase is remarkable due to the reduction in the number of samples. The test results show not statistically significant relationship due to the low number of samples, but it would be significant if the number of samples increased. Using of the electronic system while reducing the frequency of sampling and microbial testing costs; it will increase dramatically monitoring accuracy of drinking water networks and consequently the quality and safety of drinking water. These results will be consistent with the results of Farahzadi research (2010); they concluded that using of electronic systems will reduce costs and increase monitoring accuracy of drinking water networks [8].

A system manufactured by Harold and Moskoff for monitoring the quality water network in 2004. In this method, water quality monitoring device was introduced for consumer units. These monitoring devices determine water quality parameters such as microbial parameters. In this method after parameters determined, it would compare to the standard and create alarm if the parameters do not match with the standard. Data can be transmitted via a network connection or a satellite to control center, this system is an onsite device that can notify customer about the water quality. Methods of data sending and analyzing in this system have been not identified and just referred to it. Working with this system in water network control is not cost-effective in larger communities and it is the disadvantage of this system in comparison to the system in our research [9].

In 2005, the remote monitoring system of water supply was provided by Daniel, in this system a management technique is described for water monitoring, chemical parameters were determined by using of some specific sensors and results with a electrical signal send by cable to the control centers and compared with a standard signal, in case of lack of conformity, there is the possibility for the operator to intervene in the process and will decide about it. This system requires various sensors that need to be installed at check points. Using of this system is cost effective in limited areas such as water treatment plant and where chemical processes occur [13]. In 2009, a device was made by David and Frank for the investigation of several chemical parameters in drinking water that enters to distribution system. In this device a set of sensors evaluates and monitor some parameters such as heavy metals, radiological, and microbiological quality of water in the water entering to distribution system (usually in the pumping site). This system has ability to assess water quality in the beginning of water distribution system [14].

A system built by CyrilleLemone for monitoring the quality of drinking water in distribution water network in 2012. This plan includes some probes for determining and monitoring the quality and quantity of water, In addition, this system has this ability to do some control measures such as flow control and back pressure control. Use of this system in an extensive network is required to high costs and expert [11].

\section{Conclusion}

By comparing to the electronic system by conventional monitoring method in drinking water quality monitoring and other devices that were invented before, it showed that this electronic system is the best choice for water distribution network monitoring in rural areas in Iran that have wide dispersion. Use of this system increases accuracy and reduces the cost of water network monitoring.

\section{References}

[1] Ghannadi, M. and Mohebei, M.R. (2002) Guidelines for Analysis of Microbial Quality of Drinking Water. Khorasan Water and Wastewater Company, Mashhad.

[2] Dufour, A.P. (2003) Organisation for Economic Co-Operation and Development. Assessing Microbial Safety of Drinking Water: Improving Approaches and Methods. IWA Publishing, London.

[3] Ghannadi, M. (2004) Risk Assessment and Developing the Rural Drinking Water Quality Parameters. Water and Environment, 58, 32-37.

[4] Water and Wastewater Engineering Co. (2006) Annual Performance Report of Iranian Rural Water and Wastewater Companies.

[5] World Health Organization (2006) Guidelines for Drinking Water Quality. 1st Addendum to 3rd Edition, WHO, Geneva. 
[6] Ghannadi, M. (2003) Strategies for Quality Control in Water Supply Networks. Water and Environment, 52, 4-11.

[7] Mohebbi, M.R. (2007) Study of Drinking Water Quality in Village of Tehran Weakness and Options to Improve It. MS. Thesis, Tehran University of Medical Sciences, Tehran.

[8] Farahzadi, M.H., Ghadirian, D., Jafari, V. and Fallahzadeh, R.A. (2010) Reform Microbial and Chlorine Sampling Process for Increasing Quality of Monitoring, Statistical Value and Cost Reduction in Water Supply Network Controlling. 13th National Conference of Environmental Health, Kerman, 2-4 November 2010, 4-10.

[9] Harold, I.M. (2004) Water Quality Monitoring and Transmission System and Method. US Patent No. US6753186 B2.

[10] Gary, A.B. (2008) Chlorine Monitor and Recorder for Water Distribution System. US Patent No. US0017509 A1.

[11] CyrilleLemone (2012) Installation and a Method for Monitoring the Quality of Water in a Potable Water Network. US Patent No. US 20120111799 A1.

[12] Fallahzadeh, R.A., Farahzadi, M.H., Shahvazian, M.Sh. and Shahvazian, M. (2013) Electronic Device by Recording and Analysis Ability of Chlorine and PH Test Data for Monitoring of Drinking Water Network. Industrial Property General Office, IR Patent No. 77815.

[13] Daniel, V. (2005) Remote Monitoring System for Water. US Patent No. US0009192 A1.

[14] David, L.F. (2009) Real Time Water Analysis System for Metals, Chemicals Radiological and Biological Materials (CBRNME) within Water. US Patent No. US 20090125241 A1. 
Scientific Research Publishing (SCIRP) is one of the largest Open Access journal publishers. It is currently publishing more than 200 open access, online, peer-reviewed journals covering a wide range of academic disciplines. SCIRP serves the worldwide academic communities and contributes to the progress and application of science with its publication.

Other selected journals from SCIRP are listed as below. Submit your manuscript to us via either submit@scirp.org or Online Submission Portal.
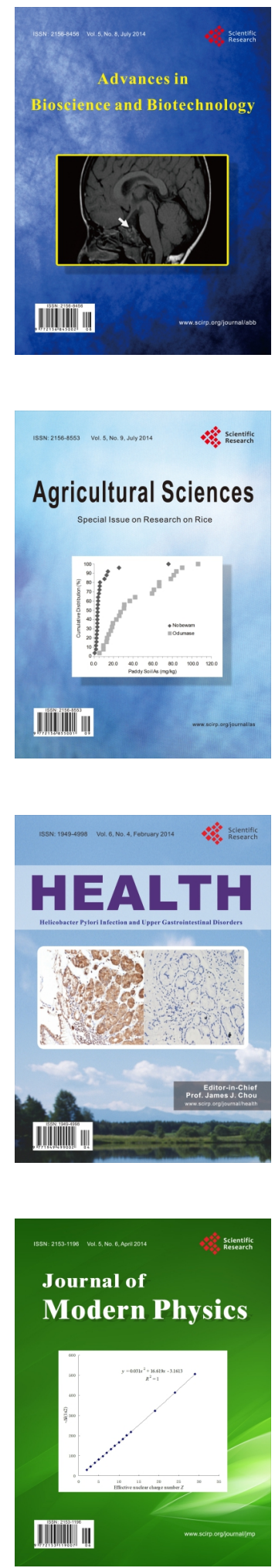
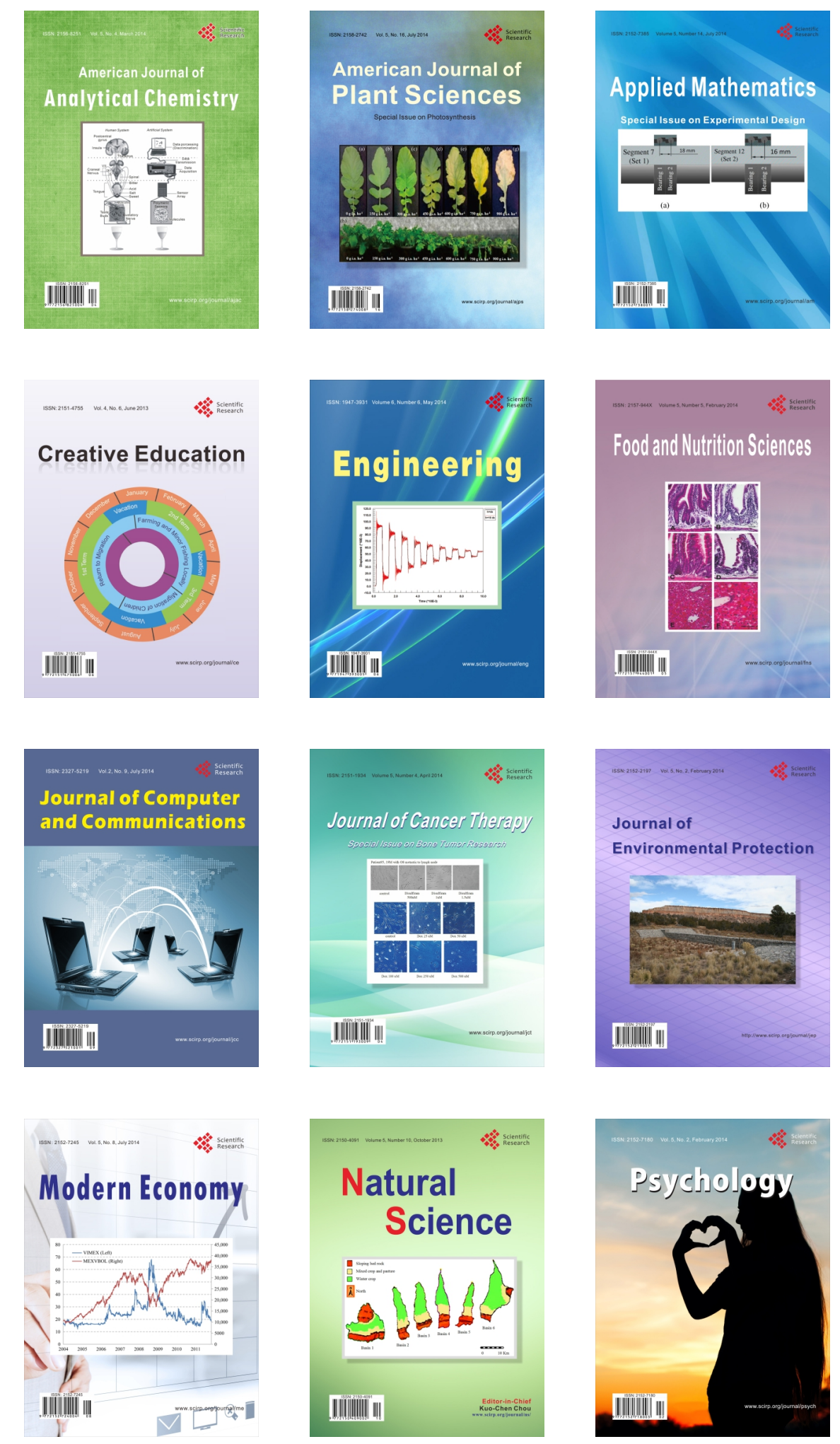